\title{
Thermal creep and relaxation of prestressing steel
}

\author{
Ya Wei, ${ }^{\mathrm{a}}$ Li Zhang, ${ }^{\mathrm{a}}$ Francis T K Au, ${ }^{\mathrm{a}}{ }^{\mathrm{J}}$ Jing $\mathrm{Li}^{\mathrm{b}}$ and Neil C M Tsang ${ }^{\mathrm{c}}$ \\ ${ }^{a}$ Department of Civil Engineering, The University of Hong Kong, Pokfulam Road, Hong Kong, China \\ ${ }^{\mathrm{b}}$ Department of Civil Engineering, South China University of Technology, Guangzhou, China \\ ${ }^{\mathrm{c}}$ School of Energy, Construction and Environment, Coventry University, UK
}

\begin{abstract}
The thermal creep and relaxation of prestressing steel are crucial to the permanent loss of prestress in post-tensioned concrete structures after fire. Harmathy’s creep model is widely used to account for the irrecoverable thermal creep strain. In view of advances in steel manufacture, it is desirable to determine the relevant parameters of Harmathy's creep model for common prestressing steel being used.
\end{abstract} Recently, Gales et al. found that the creep parameters obtained by Harmathy and Stanzak in the 1970s were out of date as the use of these parameters could not give accurate numerical results. They further identified the parameters through testing of prestressing steel to ASTM A417. This study further extended the work of Gales et al. Based on the steady state thermal creep and relaxation tests of prestressing steel to GB/T 5224 (Grade 1860) and BS 5896 (Grade 1860) over wide stress ranges, the parameters of Harmathy's thermal creep model were identified and calibrated. Using the approach of Maljaars et al., the lower limit of tertiary creep was estimated and the creep model was further fine-tuned to incorporate tertiary creep. Numerical

\footnotetext{
${ }^{*}$ Corresponding author: Professor F. T. K. Au

E-mail: francis.au@hku.hk

Tel: (852) 2859-2650; Fax: (852) 2559-5337
}

Address: Department of Civil Engineering, the University of Hong Kong, Pokfulam Road, Hong Kong, China. 
studies were conducted to examine the thermal creep and relaxation of prestressing steel at elevated temperatures using the enhanced creep model. The numerical predictions were found to agree well with the test results in respect of thermal creep and relaxation. In particular, predictions using the enhanced creep model with different sets of thermal creep parameters were compared with results of the thermal relaxation test conducted by MacLean, indicating different thermal creep resistance.

Keywords: numerical model, prestressing steel, thermal creep, thermal relaxation

\section{Introduction}

Prestressing steel tendons in the form of strands or wires are important components in post-tensioned (PT) concrete structures, which enable the structures to achieve high load-carrying capacities and large span to depth ratios. In particular, the use of PT concrete slabs in buildings is becoming popular. However in view of the relatively small concrete covers provided to the tendons in slabs as compared to those in beams, once such slabs are subjected to fire, the steel tendons carrying high stresses are quite sensitive to the ensuing elevated temperatures causing their stresses to decrease because of the thermal elongation, mechanical degradation, and thermal creep and relaxation, which further reduce their load-carrying capacities. The mechanical properties of prestressing steel at elevated temperatures have been investigated by tests, mainly covering the elastic modulus, yield strength and ultimate strength [1-6]. It is well known that the mechanical properties degrade with increasing temperature. The thermal relaxation of prestressing steel has been investigated with emphasis on the permanent loss of stress [3, 7-10].

The thermal creep of structural steel was addressed by Harmathy [11] in predicting the deformation of steel structures in fire. To solve the problem, a comprehensive creep model was proposed based on Dorn's creep theory [11]. Moreover, a series of thermal creep tests were conducted by Harmathy and Stanzak [12] to identify the parameters of the creep model, in which prestressing steel to ASTM A421 (Grade 1725) was 
investigated and its thermal creep parameters were identified as well. Recently, based on the creep model and thermal creep parameters of prestressing steel to ASTM A421 (Grade 1725), MacLean [3], Gales [7] and Gales et al. $[8,10]$ proposed a method for prediction of the thermal relaxation of prestressing steel strands with validation against their thermal relaxation tests. However, comparison with the test results indicates the predictions have overestimated the thermal relaxation, which suggests that the thermal creep parameters need updating. Afterwards, steady state and transient thermal tensile tests of prestressing steel to ASTM A416 (Grade 1860) and BS 5896 (Grade 1860) were conducted to identify the thermal creep parameters of Harmathy's creep model by Gales et al. [13, 14]. Besides, the thermal creep of prestressing steel to GB/T 5224 (Grade 1770) was investigated by Zhang and Zheng by steady state tests, proposing an empirical formula for estimating thermal creep strain [15]. However, in the determination of thermal creep parameters, Gales et al. [13, 14] assumed the same value of thermal creep activation energy obtained by Harmathy and Stanzak [12] for prestressing steel to ASTM A421 (Grade 1725), and hence the results might need further refinement. The empirical formula proposed by Zhang and Zheng may also be improved by the development of a proper theoretical model. Besides, the prestressing steel made in Mainland China to GB/T 5224 (Grade 1860) [16] and that to BS 5896 (Grade 1860) [17] widely used in many places including Hong Kong are in need of a thorough investigation of thermal creep and relaxation properties. Therefore, such investigations will be desirable for providing accurate numerical predictions.

The present study further extended the work by Gales et al. [8-10]. Steady state thermal creep and relaxation tests of prestressing steel to GB/T 5224 (Grade 1860) and BS 5896 (Grade 1860) were conducted. Based on Harmathy's creep model, the thermal creep parameters were identified using the test results. As Harmathy's creep model cannot account for tertiary creep, the model has been further modified in order that tertiary creep can be explicitly incorporated. This will help structural designers to better 
understand and model the performance of prestressing strands at elevated temperatures.

\section{Creep theory and existing model}

Creep is the time-dependent plastic strain under constant stress and temperature. Prestressing steel invariably contains some defects of microstructure, which may cause movement of lattice dislocations under high stresses or diffusion under elevated temperatures. Thermal creep deformation can take two forms, namely solid state diffusion dominated creep, and glide or sliding dominated creep [18]. The former mechanism occurs at lower stress but higher temperature, and the creep strain is governed by the rate of solid state diffusion in the bulk of crystal grains or along grain boundaries, or by extensive diffusion-assisted dislocation climb for larger grain sizes. The latter mechanism occurs at higher stress but lower temperature, and the creep strain is governed by dislocation motion assisted by vacancy diffusion, dislocation slip over crystallographic planes which prevail at room temperature, with individual grains sliding over each other under the conditions of higher stress and temperature [18].

The three stages of creep [19] are shown in Fig. 1(a). The first stage or primary creep develops rapidly but at decreasing strain rate. The second stage known as secondary creep or steady-state creep develops linearly at a strain rate that remains nearly constant. The third stage or tertiary creep is characterized by accelerated strain rate until rupture. Secondary creep is better understood among various stages at elevated temperatures, and the creep rate obeys Arrhenius's Law given by

$$
\frac{\partial \varepsilon_{c r}}{\partial t} \propto \exp \left(-\frac{Q_{c}}{R \bar{T}}\right) \quad \frac{d \sigma}{d t}=0
$$

where $\varepsilon_{c r}$ is the creep strain; $t$ is time; $Q_{c}$ is the activation energy for thermal creep, which is approximately the activation energy for lattice self-diffusion when it is above half of the melting temperature (in Kelvin); $R$ is the gas constant; $\bar{T}$ is the temperature in Kelvin; and $\sigma$ is the creep stress in MPa. 
The temperature-compensated time $\theta$ according to Dorn's creep theory as presented by Harmathy [11] is

$$
\theta=\int_{0}^{t} \exp \left(-\frac{Q_{c}}{R \bar{T}}\right) d t
$$

Differentiating Eq. 2 with respect to time $t$, and substituting into Eq. (1) give

$$
\frac{\partial \varepsilon_{c r}}{\partial \theta}=\frac{\partial \varepsilon_{c r}}{\partial t} \exp \left(\frac{Q_{c}}{R \bar{T}}\right) \equiv Z
$$

where $Z$ is the Zener-Hollomon parameter [20] as shown in Fig. 1(b), which is taken as a function of stress and independent of temperature. The dimensionless parameter $\varepsilon_{c r, 0}$ in Fig. 1(b) can be obtained by extending the straight line for secondary creep to the vertical axis, which is uniquely determined by stress and also independent of temperature.

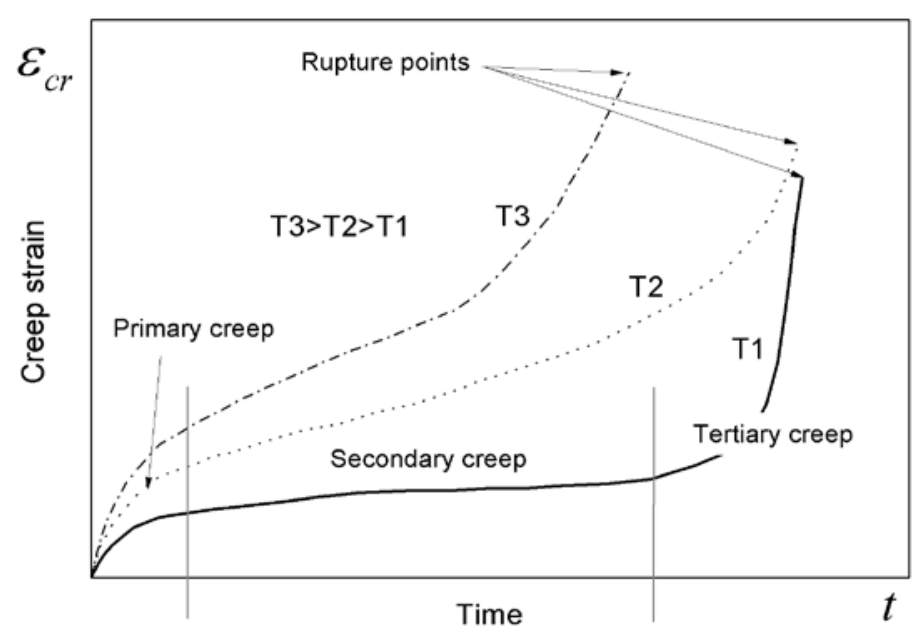

(a) Variation of creep strain with time 


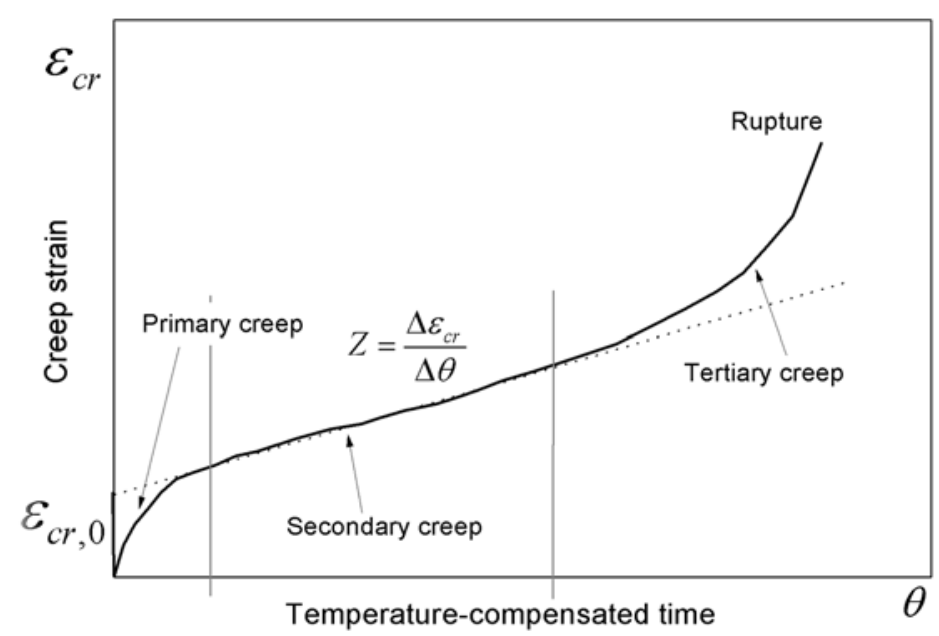

(b) Variation of creep strain with temperature-compensated time

Fig. 1. Creep strain at constant stress and temperature [19].

Harmathy [11] has proposed two equations to describe the primary thermal creep strain using the creep parameter $\varepsilon_{c r, 0}$ as

$$
\begin{array}{cc}
\frac{1}{z} \frac{d \varepsilon_{c r}}{d \theta}=\operatorname{coth}\left(\ln 2 \frac{\varepsilon_{c r}}{\varepsilon_{c r, 0}}\right) & \frac{d \sigma}{d t}=0 \\
\frac{1}{z} \frac{d \varepsilon_{c r}}{d \theta}=\operatorname{coth}^{2}\left(\frac{\varepsilon_{c r}}{\varepsilon_{c r, 0}}\right) & \frac{d \sigma}{d t}=0
\end{array}
$$

While Eq. 4 can be integrated to give

$$
\varepsilon_{c r}=\frac{\varepsilon_{c r, 0}}{\ln 2} \cosh ^{-1}\left(2^{Z \theta / \varepsilon_{c r, 0}}\right) \quad \frac{d \sigma}{d t}=0
$$

Eq. 5 cannot be integrated explicitly, but it can be expressed in terms of the creep parameter $Z$ in incremental form over a time interval as

$$
\Delta \varepsilon_{c r}=Z \operatorname{coth}^{2}\left(\frac{\varepsilon_{c r}}{\varepsilon_{c r, 0}}\right) \Delta \theta \quad \frac{d \sigma}{d t}=0
$$

However, Harmathy's model does not account for tertiary creep. Hence the approach proposed by Maljaars et al. [21] for aluminium alloys is adopted here to consider tertiary creep. As there exists a linear relationship between the creep strain rate and the creep strain at the tertiary creep stage, the modification is presented as

$$
\Delta \varepsilon_{c r}=c \cdot \varepsilon_{c r} \quad \varepsilon_{c r} \geq \varepsilon_{\text {lim }}
$$


where $c$ is a constant; $\varepsilon_{\text {lim }}$ is the creep strain at the start of tertiary creep; and $\varepsilon_{\text {lim }}$ is taken to be approximately a constant independent of load or temperature condition for simplicity [21]. Assuming continuity of the creep strain rate at the initiation of tertiary creep [21], the constant $c$ can be obtained as

$$
c=\frac{\Delta \tilde{\varepsilon}_{c r}}{\varepsilon_{\text {lim }}}
$$

where $\Delta \tilde{\varepsilon}_{c r}$ is the creep strain rate of secondary creep.

Model-1 based on Eq. 6 and Model-2 based on Eq. 7 both take tertiary creep into account for total creep strain not less than $\varepsilon_{\text {lim }}$ in Eq. 8. Both models will be further investigated in the following sections.

\section{Materials and testing}

\subsection{Materials}

As prestressing strands used in practice are reasonably long compared to their nominal diameters and the relative slip among individual wires in a strand is normally considered negligible, only the central core wires have been used for thermal creep and relaxation tests to take advantage of the available precision equipment. The prestressing steel to GB/T 5224 (Grade 1860) consists of 7-wire steel strands with a nominal diameter of 12.7 mm supplied by Tianjin Da Qiang Steel Co. Ltd. in China. The central core wire has a diameter of $4.35 \mathrm{~mm}$. The prestressing steel to BS 5896 (Grade 1860) consists of 7-wire steel strands with a nominal diameter of $15.7 \mathrm{~mm}$ supplied by Wuxi Jin Yang Metal Products Co. Ltd. in China. The central core wire has a diameter of $5.39 \mathrm{~mm}$. The chemical compositions of the strands as shown in Table 1 may affect the thermal creep properties, possibly because of different microstructures [18]. Each specimen of prestressing steel has a total length of $800 \mathrm{~mm}$ and a clear length of $650 \mathrm{~mm}$ between grips after being mounted in the testing machine. The basic mechanical properties of both types of prestressing steel at ambient and elevated temperatures obtained from tests are shown in Table 2 [22]. 
Table 1. Chemical composition of prestressing steel tested (\%)

\begin{tabular}{|c|c|c|c|c|c|}
\hline & $\begin{array}{c}\text { GB/T5224 } \\
\text { (Grade 1860) }\end{array}$ & $\begin{array}{c}\text { BS } 5896 \\
\text { (Grade 1860) }\end{array}$ & $\begin{array}{c}\text { BS } 5896 \\
\text { (Grade 1860) } \\
\text { [13] }\end{array}$ & $\begin{array}{c}\text { ASTM A416 } \\
\text { (Grade 1860) } \\
\text { [13] }\end{array}$ & $\begin{array}{c}\text { ASTM A421 } \\
\text { (Grade 1725) } \\
\text { [11] }\end{array}$ \\
\hline $\mathrm{C}$ & 0.8 & 0.8 & 0.9 & 0.8 & 0.79 \\
\hline $\mathrm{Cr}$ & - & 0.13 & 0.011 & 0.04 & - \\
\hline $\mathrm{Mn}$ & 0.73 & 0.74 & 0.66 & 0.87 & 0.78 \\
\hline $\mathrm{P}$ & 0.015 & $<0.01$ & 0.007 & 0.023 & 0.012 \\
\hline $\mathrm{Si}$ & 0.2 & 0.41 & 0.25 & 0.45 & 0.19 \\
\hline$S$ & 0.008 & 0.016 & 0.014 & 0.012 & 0.031 \\
\hline $\mathrm{Ni}$ & - & - & 0.021 & - & - \\
\hline $\mathrm{Cu}$ & - & - & 0.011 & - & - \\
\hline
\end{tabular}

Table 2. Basic mechanical properties of prestressing steel at elevated temperatures

\begin{tabular}{cccc|ccc}
\hline & \multicolumn{2}{c|}{ GB/T 5224(Grade 1860) } & \multicolumn{3}{c}{ BS 5896 (Grade 1860) } \\
\cline { 2 - 6 } Temperature & Elastic & Yield & Ultimate & Elastic & Yield & Ultimate \\
$\left({ }^{\circ} \mathrm{C}\right)$ & modulus & strength & strength & modulus & strength & strength \\
& $(\mathrm{GPa})$ & $(\mathrm{MPa})$ & $(\mathrm{MPa})$ & $(\mathrm{GPa})$ & $(\mathrm{MPa})$ & $(\mathrm{MPa})$ \\
\hline 25 & 187 & 1705 & 1900 & 195 & 1741 & 1952 \\
100 & 190 & 1679 & 1895 & 184 & 1696 & 1920 \\
200 & 181 & 1514 & 1834 & 183 & 1577 & 1853 \\
300 & 166 & 1351 & 1512 & 167 & 1356 & 1472 \\
350 & 160 & 1154 & 1241 & 159 & 1249 & 1292 \\
400 & 155 & 1051 & 1124 & 155 & 1056 & 1108 \\
500 & 108 & 544 & 603 & 111 & 524 & 623 \\
600 & 71 & 267 & 279 & 91 & 201 & 264 \\
700 & 14 & 83 & 94 & 40 & 57 & 82 \\
800 & 7 & 46 & 67 & 35 & 44 & 67 \\
\hline
\end{tabular}

Note: Yield strength is taken as the stress at $0.2 \%$ offset strain. 


\subsection{Test equipment}

The thermal creep and relaxation tests were carried out employing an MTS 810 Universal Testing Machine with a maximum tensile capacity of $250 \mathrm{kN}$. The series 647 hydraulic wedge grips were used to hold the specimen in place during testing and to provide a constant hydraulically actuated gripping force regardless of the applied test loads. The heating device used in the study was an MTS Model 653 High-Temperature Furnace with a maximum temperature of $1400^{\circ} \mathrm{C}$ and a maximum heating rate of $100^{\circ} \mathrm{C} / \mathrm{min}$, as shown in Fig. 2. The furnace had an overall height of $220 \mathrm{~mm}$ and a height of hot zone of $185 \mathrm{~mm}$ with insulation made of polycrystalline alumina fibre material. Fig. 2(a) also shows the high-temperature extensometer rods inserted into the furnace through holes in the insulation for measurement of strains. Similarly, Fig. 2(b) shows the external thermocouple inserted into the furnace through a hole in the insulation at the back of furnace. The high-temperature extensometer has a gauge length of $25 \mathrm{~mm}$ and a travel range of $2.5 \mathrm{~mm}$. Its rods with the standard V-chisel ends were directly attached to the central part of the specimen.

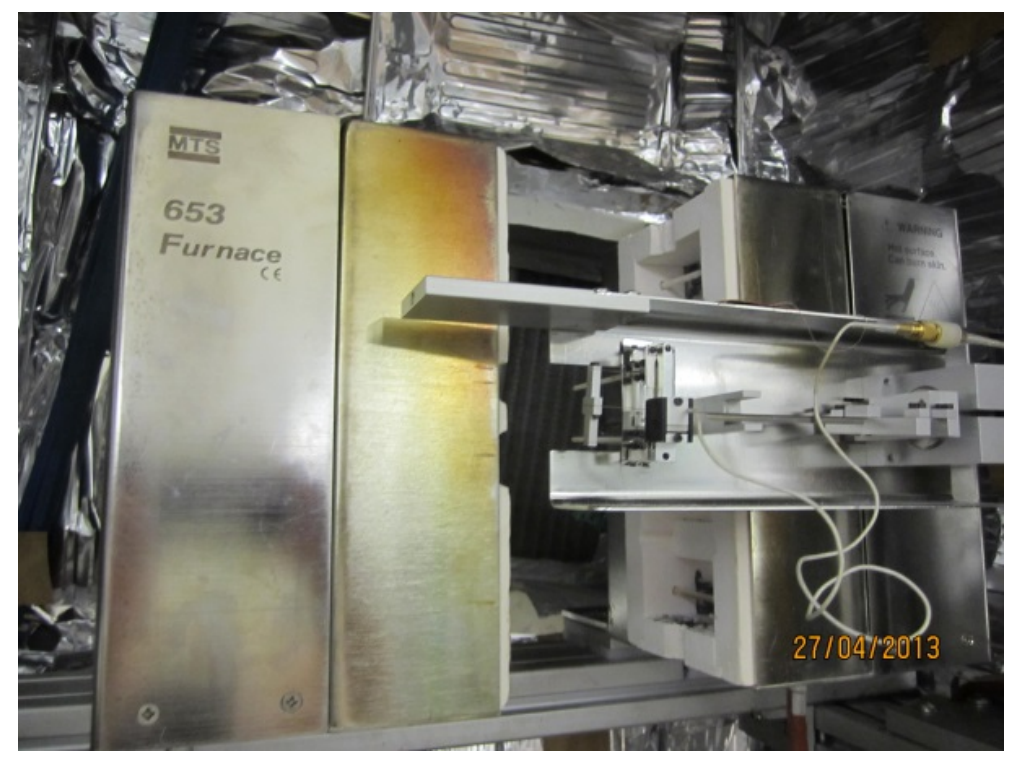

(a) Front view of furnace showing extensometer 


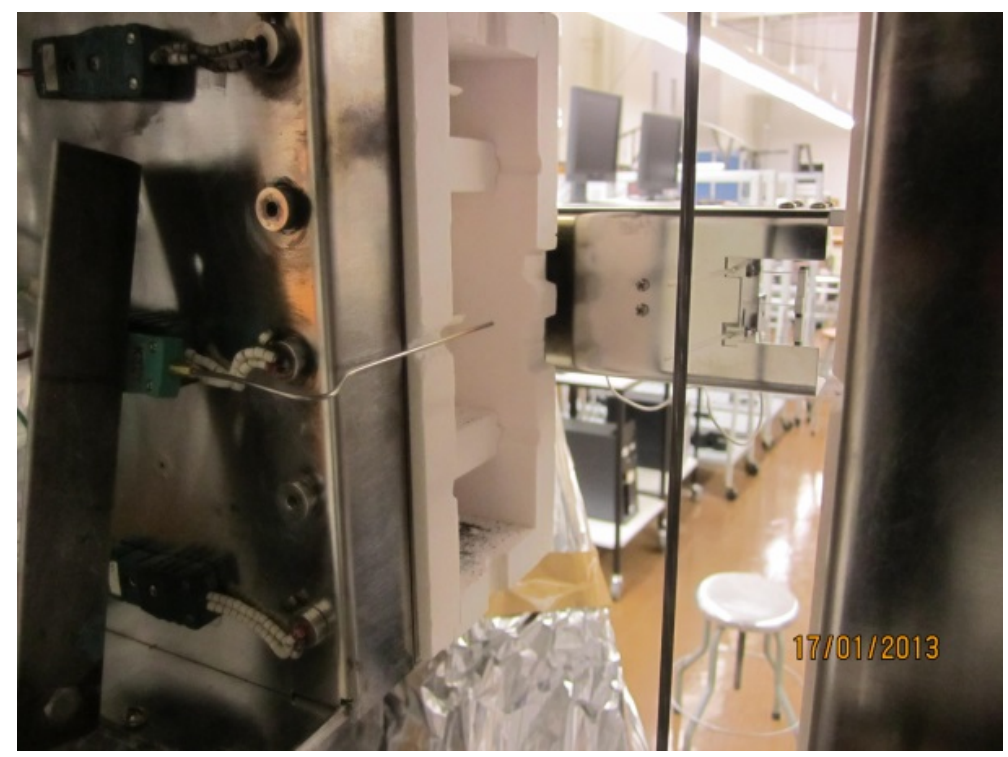

(b) Rear view of furnace showing thermocouple

Fig. 2. High-temperature furnace used.

The schematic diagram in Fig. 3 shows all the components related to the test. In particular, the specimen went through the furnace with the ends gripped by the upper and lower grips. The external thermocouple was directly attached to the specimen at the middle of the gauge length of the extensometer. To maintain a stable ambient environment immediately outside the furnace, a chamber cover was used to enclose a space called the environmental chamber including the furnace, upper and lower grips as shown in the diagram, where a ventilation window was provided in the chamber cover to allow ventilation. Nevertheless, fluctuations of temperature were observed with a maximum range of about $6^{\circ} \mathrm{C}$. The temperatures reported are average temperature with an error of about $\pm 3^{\circ} \mathrm{C}$. 


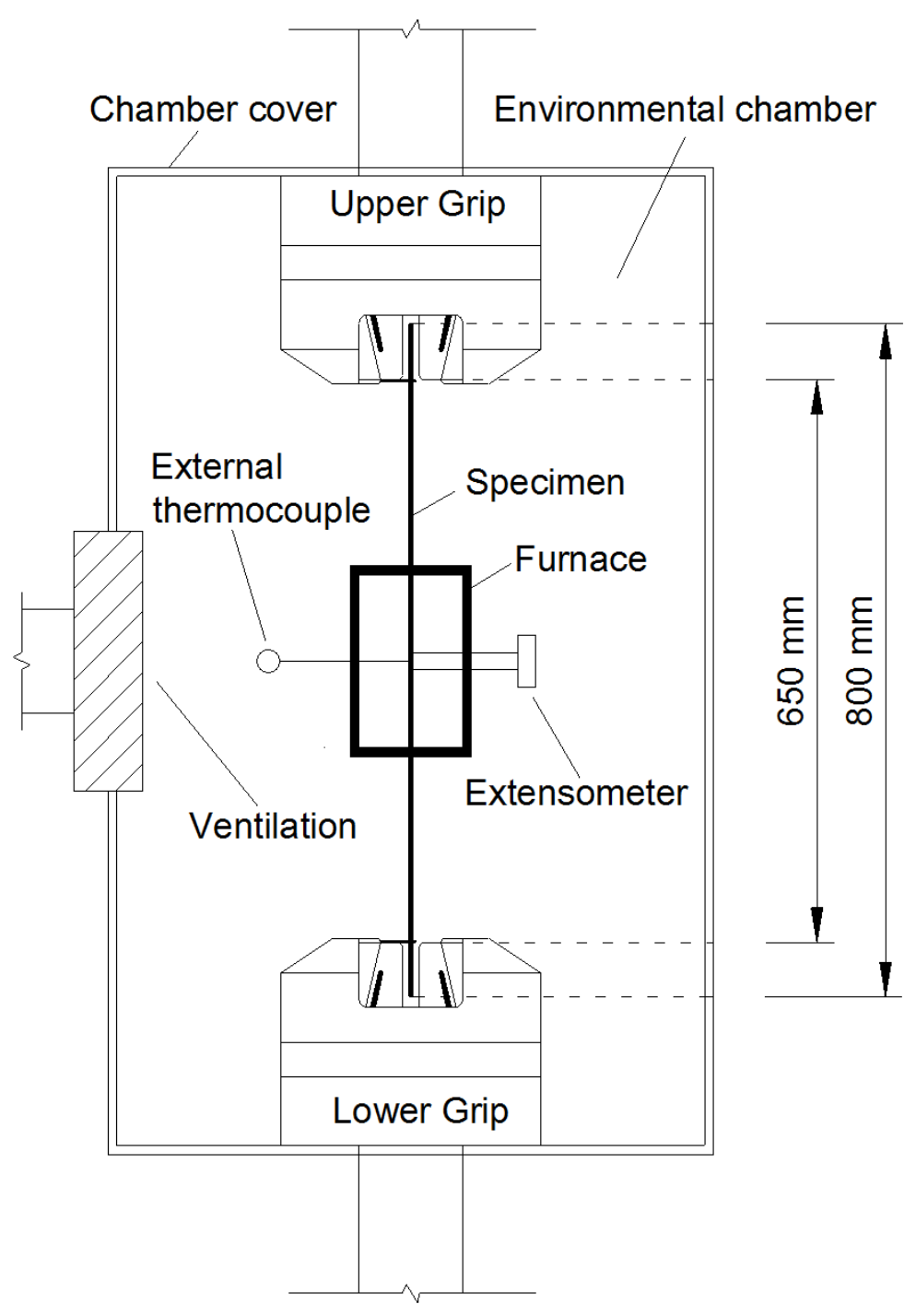

Fig. 3. Schematic diagram of test setup.

\subsection{Test procedures}

The thermal creep tests were carried out strictly in compliance with ASTM E139-11 [23]. Typically, the specimen was firstly mounted in the testing machine with the two ends gripped, and then the furnace was closed with the extensometer and thermocouple attached to the specimen for measurement. Secondly, the furnace was heated at a controlled rate depending on the target temperature $T_{t}\left(10^{\circ} \mathrm{C} / \mathrm{min}\right.$ for $T_{t} \leq 300^{\circ} \mathrm{C}$; $15^{\circ} \mathrm{C} / \mathrm{min}$ for $300^{\circ} \mathrm{C}<T_{t} \leq 500^{\circ} \mathrm{C}$; and $20^{\circ} \mathrm{C} / \mathrm{min}$ for $T_{t}>500^{\circ} \mathrm{C}$ ) to ensure reasonable time for heating, during which the force in the specimen was maintained zero automatically. When the target temperature 
was reached as indicated by the measurement of external thermocouple, the heating rate was set to be zero and the furnace temperature was kept approximately constant. Thirdly, after a period of $30 \mathrm{~min}$ for temperature stability as recorded by the external thermocouple, a uniform temperature distribution across the sectional area of the specimen was nearly achieved. Afterwards, the specified tensile force was applied to the specimen in 1 min and was then kept constant for 2 hours by force-control, during which the strain was recorded by the extensometer until the specimen ruptures or the test was ended manually, whichever was earlier.

The thermal relaxation tests were carried out to ASTM E328-02 [24] with some modifications. Firstly, the specimen was mounted in the testing machine with the two ends gripped, and then the furnace was closed with the thermocouple attached to the specimen. Secondly, the furnace was heated at a controlled rate of $10^{\circ} \mathrm{C} /$ min to $20^{\circ} \mathrm{C} /$ min depending on the target temperature as before, during which the force in the specimen was maintained zero automatically. When the target temperature was reached as indicated by the measurement of external thermocouple, the heating rate was set to be zero and the furnace temperature was automatically kept constant. Thirdly, after a period of $30 \mathrm{~min}$ for temperature stability, the specified initial tensile force was applied to the specimen in 1 min and then the clear length between grips was kept constant for 2 hours by displacement-control, during which the tensile force in the specimen was recorded. Note that the clear distance between grips was $650 \mathrm{~mm}$ while the heated length was $185 \mathrm{~mm}$ only as governed by the internal dimensions of the furnace.

This paper reports the results from 22 tests of specimens to GB/T 5224 and 26 tests of specimens to BS 5896. In the tests, minor variation of the furnace temperature was unavoidable. As the central part of temperature record that corresponded roughly to secondary creep tended to be more stable, the average temperature and standard deviation for each case were worked out and reported. The secondary creep rate 
was then determined accordingly using Fig. 4.

\section{Thermal creep}

The thermal creep tests of prestressing steel to GB/T 5224 (Grade 1860) were conducted at constant stresses of $0.7 f_{u}, 0.6 f_{u}, 0.5 f_{u}, 0.4 f_{u}, 0.3 f_{u}, 0.2 f_{u}, 0.1 f_{u}, 0.05 f_{u}$ and $0.03 f_{u}$, where the ultimate strength at ambient temperature was $f_{u}=1900 \mathrm{MPa}$. The nominal test temperatures were $300^{\circ} \mathrm{C}, 335^{\circ} \mathrm{C}$, $350^{\circ} \mathrm{C}, 375^{\circ} \mathrm{C}, 400^{\circ} \mathrm{C}, 425^{\circ} \mathrm{C}, 450^{\circ} \mathrm{C}, 500^{\circ} \mathrm{C}, 600^{\circ} \mathrm{C}$ and $650^{\circ} \mathrm{C}$. For the prestressing steel to BS 5896 (Grade 1860), the applied constant stresses were $0.70 f_{u}, 0.65 f_{u}, 0.60 f_{u}, 0.55 f_{u}, 0.50 f_{u}, 0.45 f_{u}$, $0.40 f_{u}, 0.35 f_{u}, 0.30 f_{u}, 0.25 f_{u}, 0.20 f_{u}, 0.15 f_{u}$ and $0.10 f_{u}$, where the ultimate strength at ambient temperature was $f_{u}=1952 \mathrm{MPa}$. The nominal test temperatures were $300^{\circ} \mathrm{C}, 350^{\circ} \mathrm{C}, 375^{\circ} \mathrm{C}, 400^{\circ} \mathrm{C}$, $450^{\circ} \mathrm{C}, 500^{\circ} \mathrm{C}$ and $550^{\circ} \mathrm{C}$. It was necessary to keep the applied stress on a test specimen below its yield strength at test temperature, which was taken as the stress at $0.2 \%$ offset strain. While the applied stress can be controlled with precision, it is more difficult to control the furnace temperature accurately. The test temperatures reported are the average values based on measurements.

\subsection{Determination of thermal creep parameters}

Based on the test results, the thermal creep parameters of Harmathy's thermal creep model were determined. The activation energy for thermal creep $Q_{c}$ was determined at various elevated temperatures with the same applied constant stress. The Zener-Hollomon parameter $Z$ was determined for various applied constant stresses at the same elevated temperature.

The relations between the logarithms of thermal creep rates and the reciprocals of the corresponding temperatures (in Kelvin) for various applied constant stresses are shown in Fig. 4. There is an approximate linear relation for both types of prestressing steel, which further confirms that Eq. 1 is applicable and the 
slope of each curve is $-Q_{c} / R$. Obviously, the activation energy for thermal creep $Q_{c}$ is nearly constant for various constant stresses, which confirms that $Q_{c}$ is independent of temperature (for those above half of melting temperature in Kelvin) and stress (except for extremely high stresses) as presented by Harmathy [10]. It also indicates that thermal creep is dominated by the creep mechanism of solid state diffusion at elevated temperatures. Based on the average slope of the curves for prestressing steel to GB/T 5224 (Grade 1860) as shown in Fig. 4(a), $Q_{c}=347.71 \mathrm{~kJ} / \mathrm{mol}$ was obtained. Similarly, Fig. 4(b) gives $Q_{c}=338.44$ $\mathrm{kJ} / \mathrm{mol}$ for prestressing steel to BS 5896 (Grade 1860).

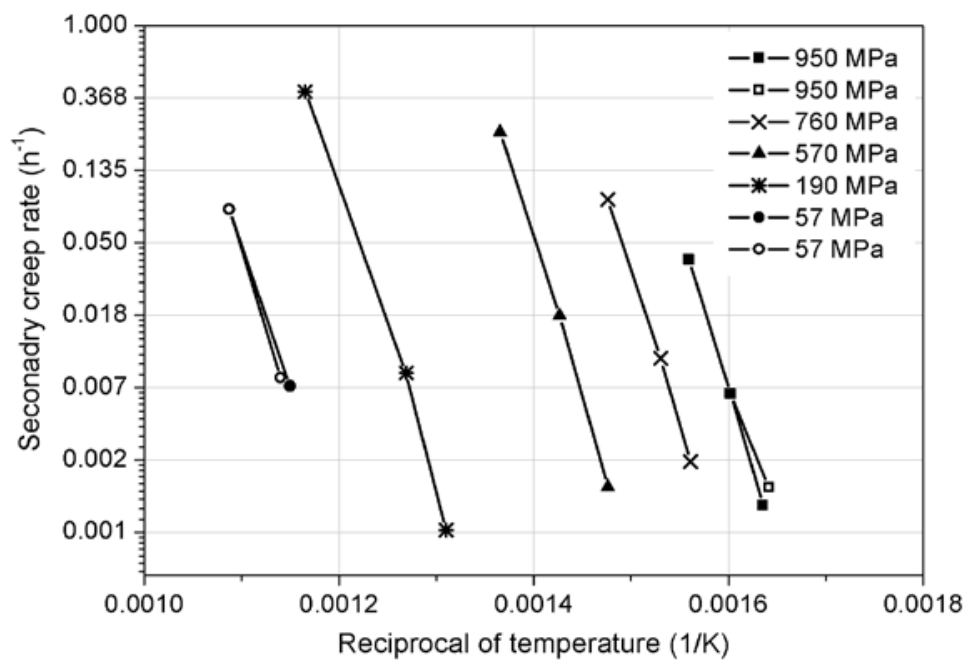

(a) Prestressing steel to GB/T 5224 (Grade 1860)

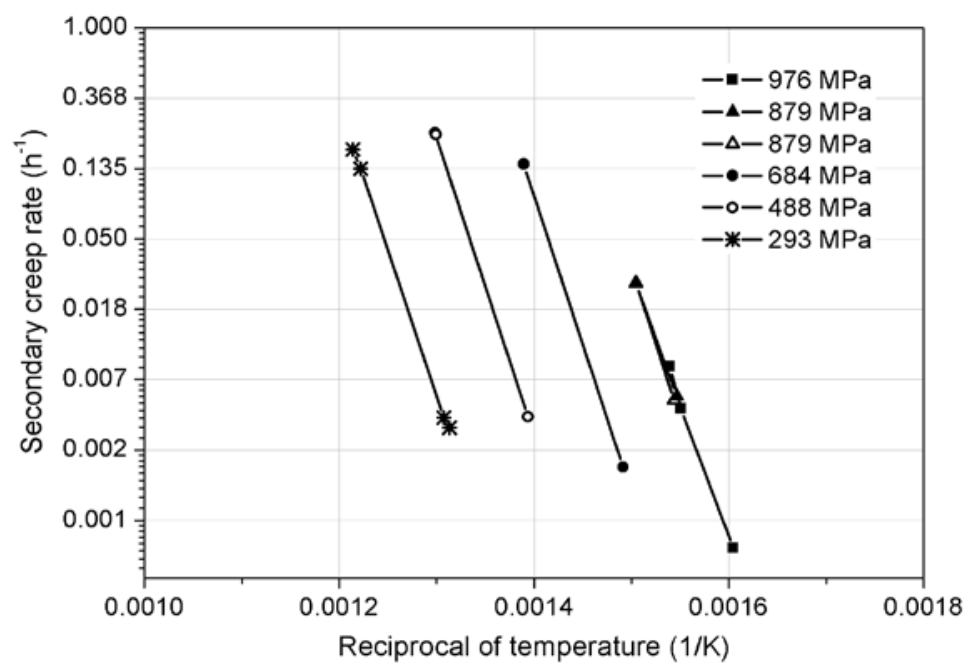

(b) Prestressing steel to BS 5896 (Grade 1860)

Fig. 4. Relation between secondary creep rate and reciprocal of temperature under various constant stresses. 
Based on the value of activation energy for thermal creep $Q_{c}$ obtained, the Zener-Hollomon parameter $Z$ can be calculated from Eq. 3. The effects of stress on the temperature-compensated secondary thermal creep rate can be examined by plotting the logarithm of $Z$ against the corresponding stress as shown in Fig. 5, which shows that $Z$ is monotonically increasing and stress-dependent. Hence, there is no simple model to describe the relation between $Z$ and the stress. Based on the test results as shown in Fig. 5(a), the relation between $Z$ and the stress for prestressing steel to GB/T 5224 (Grade 1860) within the stress range from $57 \mathrm{MPa}$ to $1330 \mathrm{MPa}$ was obtained by regression analysis as

$$
\begin{array}{lr}
\mathrm{Z}=3.63155 \times 10^{16} \exp \left(0.50851 \sigma^{0.56095}\right) & 57 \mathrm{MPa} \leq \sigma<950 \mathrm{MPa} \\
\mathrm{Z}=6.8317 \times 10^{17} \exp (0.02199 \sigma) & 950 \mathrm{MPa} \leq \sigma \leq 1330 \mathrm{MPa}
\end{array}
$$

Similarly, based on the test results as shown in Fig. 5(b), the relation for prestressing steel BS 5896 (Grade 1860) within the stress range from $195 \mathrm{MPa}$ to $1367 \mathrm{MPa}$ was obtained as

$$
\begin{array}{ll}
\mathrm{Z}=4.53651 \times 10^{18} \exp (0.01677 \sigma) & 195 \mathrm{MPa} \leq \sigma<879 \mathrm{MPa} \\
\mathrm{Z}=1.0432 \times 10^{25} \exp \left(2.61801 \times 10^{-60} \sigma^{19.70602}\right) & 879 \mathrm{MPa} \leq \sigma<1074 \mathrm{MPa} \\
\mathrm{Z}=2.55135 \times 10^{13} \exp (0.02626 \sigma) & 1074 \mathrm{MPa} \leq \sigma \leq 1367 \mathrm{MPa}
\end{array}
$$

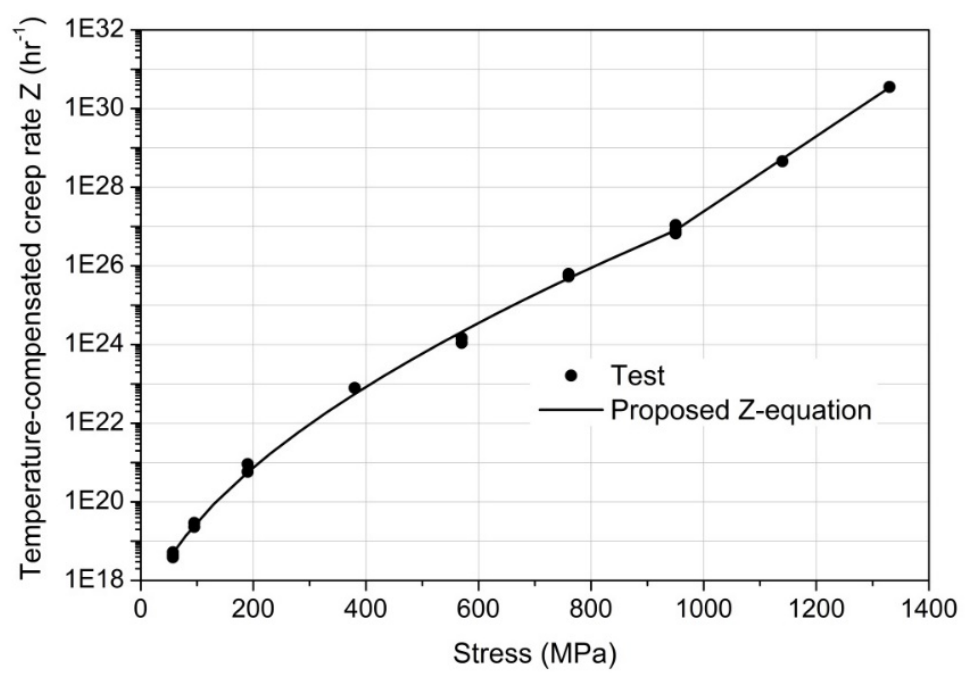

(a) Prestressing steel to GB/T 5224 (Grade 1860) 


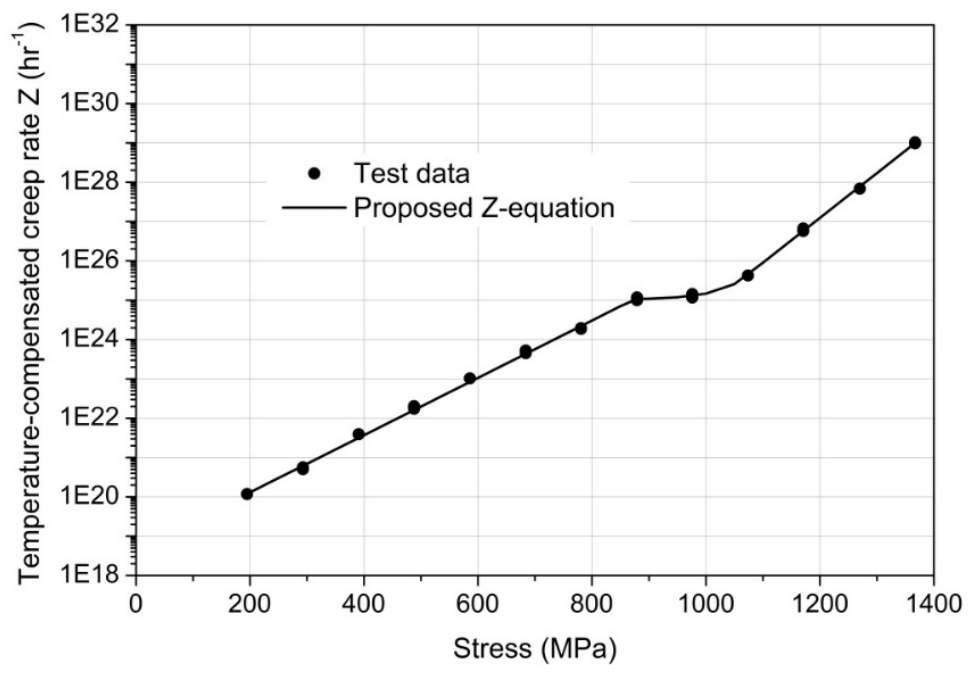

(b) Prestressing steel to BS 5896 (Grade 1860)

Fig. 5. Relation between temperature-compensated secondary thermal creep rate and stress.

The dimensionless parameter $\varepsilon_{c r, 0}$ was determined by extending the straight line for secondary creep in Fig. 1 to the axis for creep strain. Based on the test results, the values of $\varepsilon_{c r, 0}$ were obtained for various stresses and plotted in Fig 6 showing more scatter of data. To describe the effects of stress on $\varepsilon_{c r, 0}$ for prestressing steel to GB/T 5224 (Grade 1860), an empirical formula was obtained from regression using the data shown in Fig. 6(a) as

$$
\varepsilon_{\mathrm{cr}, 0}=0.00111+1.08242 \times 10^{-15} \sigma^{4.14132} \quad 57 \mathrm{MPa} \leq \sigma \leq 1330 \mathrm{MPa}
$$

Similarly, an empirical formula was obtained from the data shown in Fig. 6(b) as

$$
\varepsilon_{\mathrm{cr}, 0}=0.00123+3.81336 \times 10^{-42} \sigma^{12.52348} \quad 195 \mathrm{MPa} \leq \sigma \leq 1367 \mathrm{MPa}
$$




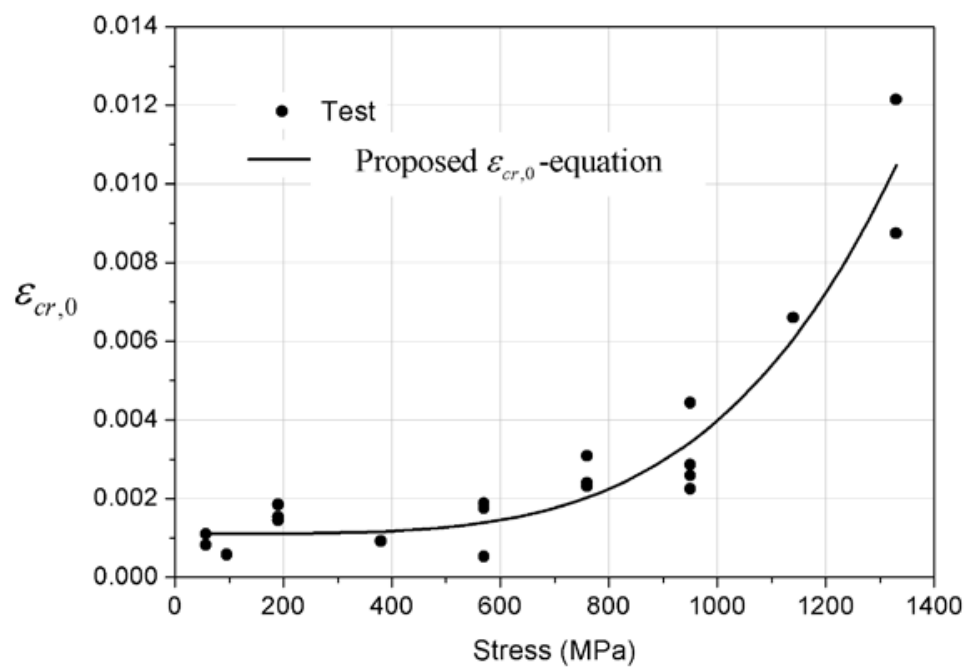

(a) Prestressing steel to GB/T 5224 (Grade 1860)

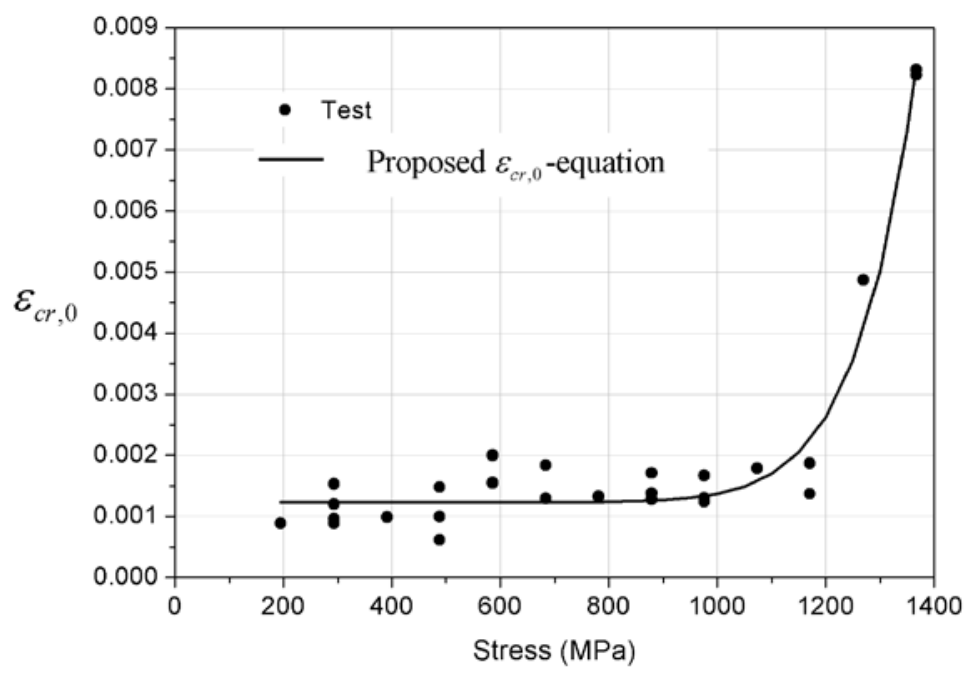

(b) Prestressing steel to BS 5896 (Grade 1860)

Fig. 6. Relation between $\varepsilon_{c r, 0}$ and stress.

In view of the extremely large variations of $Z$ as evident from the semi-log plot in Fig. 5, the agreement between the proposed empirical equation and test data was quantified in terms of the error of $\ln (Z)$. Tables 3 and 4 show the results for prestressing steel to GB/T 5224 and BS 5896 respectively. Theoretically, $Z$ values from tests under the same stress should be identical, but some $Z$ values may slightly deviate from others due to test errors or material defects. This may further increase or offset the percentage errors of $\ln (Z)$ in Tables 3 and 4 with the maximum values of $1.16 \%$ and $0.44 \%$ respectively. The agreement can be considered reasonably good. Actually, the percentage errors are induced by test data scatter and regression 
fitting, and these percentage errors may cause certain discrepancies between model predictions and test data.

Table 3. Test results of prestressing steel to GB/T 5224

\begin{tabular}{cccccc}
\hline \multirow{2}{*}{ Stress (MPa) } & \multicolumn{2}{c}{ Temperature $\left({ }^{\circ} \mathrm{C}\right)$} & & $\ln Z$ & \\
\cline { 3 - 5 } & Average & Std. deviation & Test & Equation & Error \\
\hline 1330 & 295.0 & 1.5 & 70.3463 & 70.3122 & $-0.05 \%$ \\
1330 & 300.0 & 1.7 & 70.3472 & 70.3122 & $-0.05 \%$ \\
1140 & 336.8 & 0.6 & 65.9924 & 66.1341 & $0.21 \%$ \\
950 & 336.2 & 0.4 & 62.2534 & 61.9560 & $-0.48 \%$ \\
950 & 338.3 & 2.0 & 61.7647 & 61.9560 & $0.31 \%$ \\
950 & 351.1 & 1.4 & 61.9027 & 61.9560 & $0.09 \%$ \\
950 & 368.2 & 1.8 & 61.9717 & 61.9560 & $-0.03 \%$ \\
760 & 367.5 & 1.5 & 59.2493 & 59.1345 & $-0.19 \%$ \\
760 & 380.4 & 0.5 & 59.3918 & 59.1345 & $-0.43 \%$ \\
760 & 404.4 & 0.3 & 59.3234 & 59.1345 & $-0.32 \%$ \\
570 & 404.3 & 0.5 & 55.3602 & 56.0044 & $1.16 \%$ \\
570 & 427.9 & 0.5 & 55.6487 & 56.0044 & $0.64 \%$ \\
570 & 459.4 & 1.1 & 55.6177 & 56.0044 & $0.70 \%$ \\
380 & 493.8 & 1.1 & 52.7253 & 52.3684 & $-0.68 \%$ \\
190 & 490.2 & 1.4 & 47.8115 & 47.7819 & $-0.06 \%$ \\
190 & 515.0 & 1.8 & 48.2634 & 47.7819 & $-1.00 \%$ \\
190 & 585.0 & 1.5 & 47.8184 & 47.7819 & $-0.08 \%$ \\
95 & 592.5 & 3.3 & 44.5924 & 44.6729 & $0.18 \%$ \\
95 & 592.4 & 0.3 & 44.8195 & 44.6729 & $-0.33 \%$ \\
57 & 596.7 & 1.4 & 43.0967 & 43.0430 & $-0.12 \%$ \\
57 & 604.1 & 0.7 & 42.8078 & 43.0430 & $0.55 \%$ \\
57 & 646.7 & 0.6 & 42.9244 & 43.0430 & $0.28 \%$ \\
\hline & & & & \\
\hline
\end{tabular}


Table 4. Test results of prestressing steel to BS 5896

\begin{tabular}{|c|c|c|c|c|c|}
\hline \multirow{2}{*}{$\begin{array}{l}\text { Stress } \\
(\mathrm{MPa})\end{array}$} & \multicolumn{2}{|c|}{ Temperature $\left({ }^{\circ} \mathrm{C}\right)$} & \multicolumn{3}{|c|}{$\ln Z$} \\
\hline & Average & Std. deviation & Test & Equation & Error \\
\hline 1367 & 310.0 & 1.5 & 66.8142 & 66.7679 & $-0.07 \%$ \\
\hline 1367 & 311.2 & 1.0 & 66.7486 & 66.7679 & $0.03 \%$ \\
\hline 1270 & 304.7 & 1.0 & 64.0940 & 64.2201 & $0.20 \%$ \\
\hline 1171 & 356.0 & 0.9 & 61.7663 & 61.6199 & $-0.24 \%$ \\
\hline 1171 & 360.6 & 1.5 & 61.6181 & 61.6199 & $0.00 \%$ \\
\hline 1074 & 352.1 & 0.8 & 59.0092 & 59.0092 & $0.00 \%$ \\
\hline 976 & 350.1 & 0.6 & 57.9223 & 57.8193 & $-0.18 \%$ \\
\hline 976 & 371.7 & 0.6 & 57.7130 & 57.8193 & $0.18 \%$ \\
\hline 976 & 376.6 & 0.6 & 57.8347 & 57.8193 & $-0.03 \%$ \\
\hline 879 & 374.5 & 1.1 & 57.5576 & 57.6323 & $0.13 \%$ \\
\hline 879 & 373.4 & 1.2 & 57.7216 & 57.6323 & $-0.15 \%$ \\
\hline 879 & 391.5 & 0.7 & 57.6134 & 57.6323 & $0.03 \%$ \\
\hline 781 & 403.5 & 1.1 & 55.9299 & 56.0550 & $0.22 \%$ \\
\hline 781 & 391.2 & 0.9 & 55.8933 & 56.0550 & $0.29 \%$ \\
\hline 684 & 397.4 & 1.2 & 54.4635 & 54.4296 & $-0.06 \%$ \\
\hline 684 & 446.5 & 0.3 & 54.6234 & 54.4296 & $-0.35 \%$ \\
\hline 586 & 444.3 & 1.1 & 52.9987 & 52.7863 & $-0.40 \%$ \\
\hline 488 & 444.3 & 0.8 & 51.2050 & 51.1455 & $-0.12 \%$ \\
\hline 488 & 497.0 & 0.7 & 51.3550 & 51.1455 & $-0.41 \%$ \\
\hline 488 & 496.5 & 0.4 & 51.3698 & 51.1455 & $-0.44 \%$ \\
\hline 391 & 495.2 & 0.5 & 49.7178 & 49.5143 & $-0.41 \%$ \\
\hline 293 & 488.3 & 0.7 & 47.7763 & 47.8730 & $0.20 \%$ \\
\hline 293 & 491.7 & 0.4 & 47.6770 & 47.8730 & $0.41 \%$ \\
\hline 293 & 545.1 & 0.4 & 47.7473 & 47.8730 & $0.26 \%$ \\
\hline 293 & 550.7 & 0.9 & 47.6750 & 47.8730 & $0.42 \%$ \\
\hline 195 & 547.0 & 0.7 & 46.2172 & 46.2257 & $0.02 \%$ \\
\hline
\end{tabular}

\subsection{Model predictions}

Based on the thermal creep parameters obtained above, Model-1 and Model-2 as elaborated by Wei and Au

[25] were used to predict the thermal creep strain of prestressing steel under constant stresses and elevated

temperatures. Besides, tertiary creep was also predicted with the lower limit of tertiary creep strain being taken approximately as 0.02 (i.e. $\varepsilon_{\text {lim }}=0.02$ ) for the stress and temperature ranges tested. Theoretically, the test data under the same constant stress should follow exactly the same temperature-compensated 
thermal creep curve. However, some test data may deviate from others to some extent due to test errors, material defects or slightly different creep mechanisms at different elevated temperatures.

Figs. 7 and 8 show the model predictions based on test data of prestressing steel to GB/T 5224 and BS 5896, respectively. Fig. 7(a) shows that model prediction was compared with the tests data under the constant stress of 760MPa, in which good agreement was achieved with the test data at temperatures of $404.4^{\circ} \mathrm{C}$ and $367.5^{\circ} \mathrm{C}$. However, the test data at temperature of $380.4^{\circ} \mathrm{C}$ slightly deviates from the others possibly due to test errors induced by temperature fluctuation in the furnace. Fig. 7(b) shows the model prediction and test data under the constant stress of 950MPa, in which relatively good agreement was achieved at various elevated temperatures in spite that the test data are slightly scattered. Fig. 8(a) shows that good agreement was achieved between the model prediction and test data under the constant stress of $684 \mathrm{MPa}$, and tertiary creep was approximately predicted as well. Still, Fig. 8(b) shows model prediction agrees well with the test data under the constant stress of 976MPa at various elevated temperatures. Thus, the model predictions are relatively accurate. More importantly, the models with the determined parameters were further verified in predicting thermal relaxation of prestressing steel at elevated temperatures.

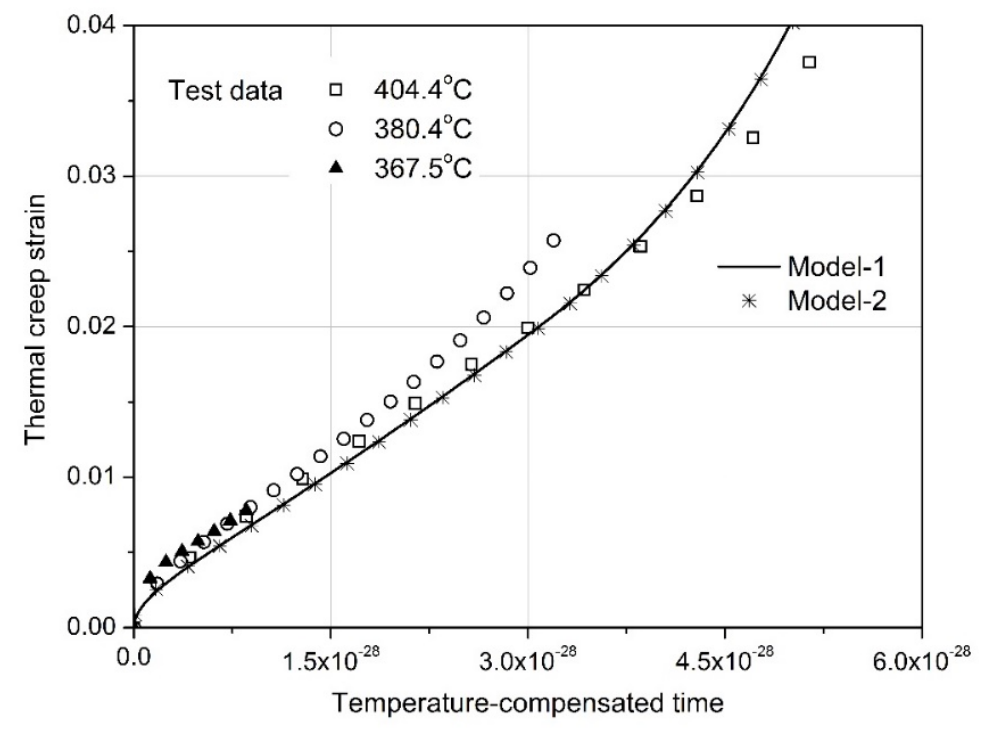

(a) Test data under constant stress of 760MPa 


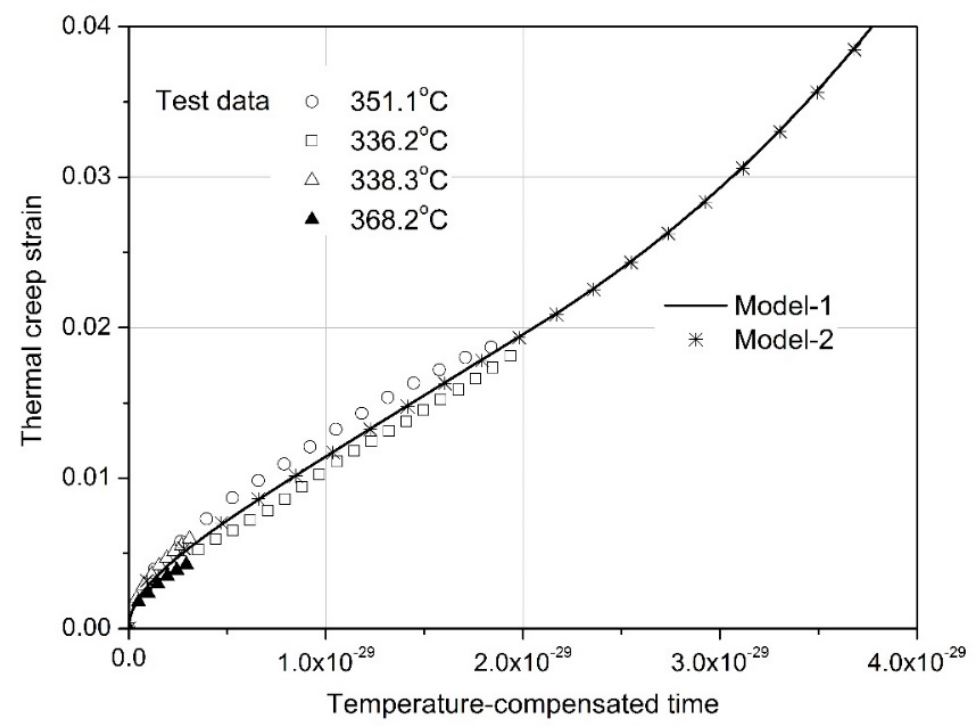

(b) Test data under constant stress of 950MPa

Fig. 7. Model predictions based on the test data of prestressing steel to GB/T 5224

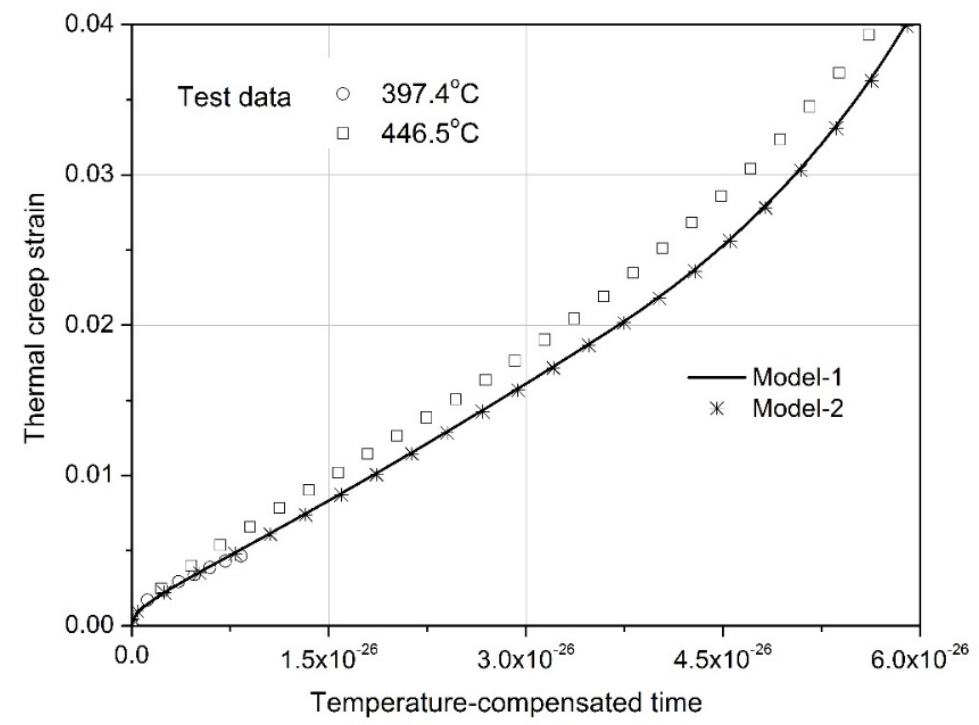

(a) Test data under constant stress of $684 \mathrm{MPa}$ 


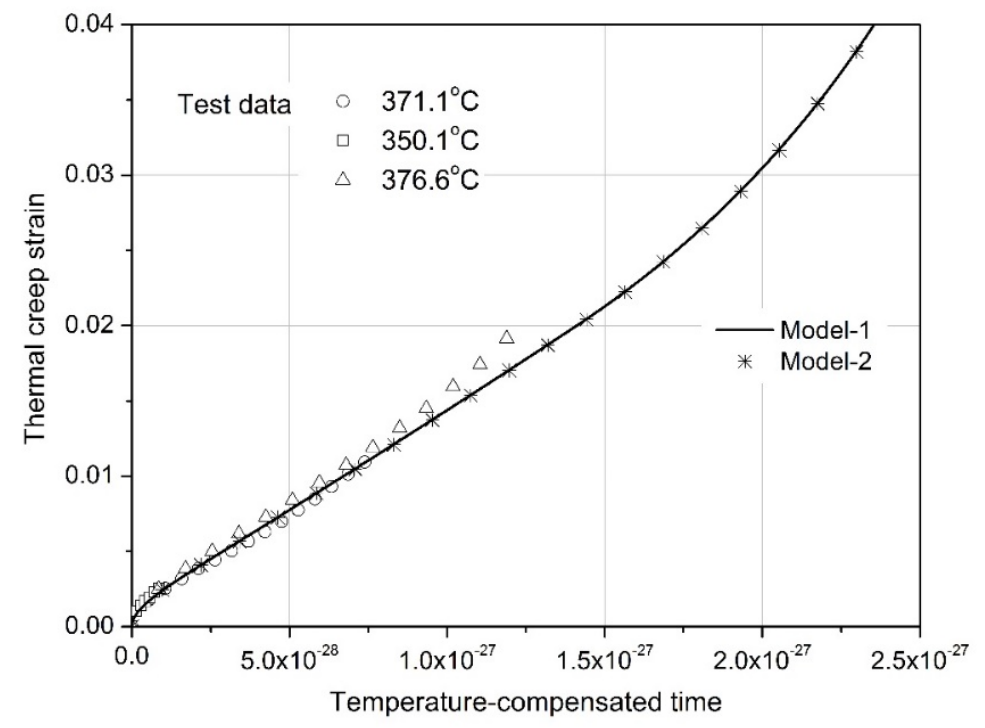

Test data under constant stress of 976MPa

Fig. 8. Model predictions based on the test data of prestressing steel to BS 5896

\section{Thermal relaxation}

To verify the applicability of the thermal creep models and determined parameters to the thermal relaxation behaviour of prestressing steel, thermal relaxation tests of prestressing steel were conducted. Table 5 shows tests of six regular cases and a repeated case carried out on prestressing steel to GB/T 5224 (Grade 1860) with the initial stress from $186 \mathrm{MPa}$ to $1325 \mathrm{MPa}$ at elevated temperatures from $300^{\circ} \mathrm{C}$ to $600^{\circ} \mathrm{C}$. Similarly, Table 6 shows tests of six regular cases and a repeated case carried out on prestressing steel to BS 5896 (Grade 1860) with the initial stress from 488MPa to $1365 \mathrm{MPa}$ at elevated temperatures from $300^{\circ} \mathrm{C}$ to $500^{\circ} \mathrm{C}$. Analysis using the numerical models took into account the heated length and the total tested length, as well as their difference in temperature and tendency of thermal creep. As the measured temperatures of the parts of total tested length outside the heated length were normally below $50^{\circ} \mathrm{C}$ at which temperature thermal creep could be considered negligible, the overall behaviour of the test was governed by the thermal creep of heated length inside the furnace, as verified by Gales' group [7-10]. The stresses after 2 hours of 
relaxation obtained from tests and numerical models are presented in Tables 5 and 6 as well as Fig. 9. Most of the model predictions have good agreement with the test data. In comparison, numerical modelling is more accurate in relaxation tests than in creep tests, as errors in creep modelling in the former do not propagate as much as in the latter. Actually relaxation is more relevant to prestressed concrete structures as the total strain is almost unchanged. In particular, a higher creep strain tends to reduce the tendon stress in this case, thereby relieving further increase in creep strain.

Table 5. Thermal relaxation tests of prestressing steel to GB/T 5224 (Grade 1860)

\begin{tabular}{ccccccc}
\hline \multirow{2}{*}{ Cases } & Nominal & True temp. & Initial stress & \multicolumn{3}{c}{ Stress after 2 hours (MPa) } \\
\cline { 5 - 7 } & Temp. $\left({ }^{\circ} \mathrm{C}\right)$ & $\left({ }^{\circ} \mathrm{C}\right)$ & $(\mathrm{MPa})$ & Test & Model-1 & Model-2 \\
\hline Case-1 & 300 & 289.8 & 1325 & 1013 & 1073.19 & 1096.86 \\
Case-2 & 350 & 352.6 & 1134 & 755 & 736.54 & 773.35 \\
Case-2* & 350 & 345.2 & 1136 & 767 & 780.20 & 819.73 \\
Case-3 & 400 & 400.2 & 943 & 459 & 476.28 & 491.92 \\
Case-4 & 435 & 436.6 & 758 & 333.7 & 316.60 & 329.60 \\
Case-5 & 500 & 505.9 & 378 & 64.3 & 114.68 & 125.85 \\
Case-6 & 600 & 597.1 & 186 & 13.7 & 0.16 & 5.58 \\
\hline
\end{tabular}

Note: * indicates repeated test 
Table 6. Thermal relaxation tests of prestressing steel to BS 5896 (Grade 1860)

\begin{tabular}{ccccccc}
\hline \multirow{2}{*}{ Cases } & Nominal & Actual & Initial stress & \multicolumn{3}{c}{ Stress after 2 hours (MPa) } \\
\cline { 5 - 7 } & Temp. $\left({ }^{\circ} \mathrm{C}\right)$ & Temp. $\left({ }^{\circ} \mathrm{C}\right)$ & $(\mathrm{MPa})$ & Test & Model-1 & Model-2 \\
\hline Case-1 & 300 & 296.6 & 1365 & 1158 & 1185 & 1205 \\
Case-2 & 350 & 347.1 & 1075 & 944 & 955 & 961 \\
Case-2 $*$ & 350 & 348.9 & 1074 & 951 & 944 & 951 \\
Case-3 & 400 & 394.0 & 974 & 583 & 619 & 632 \\
Case-4 & 400 & 396.2 & 878 & 577 & 604 & 618 \\
Case-5 & 450 & 448.0 & 586 & 379 & 347 & 360 \\
Case-6 & 500 & 498.7 & 488 & 124 & 137 & 148 \\
\hline
\end{tabular}

Note: * indicates repeated test

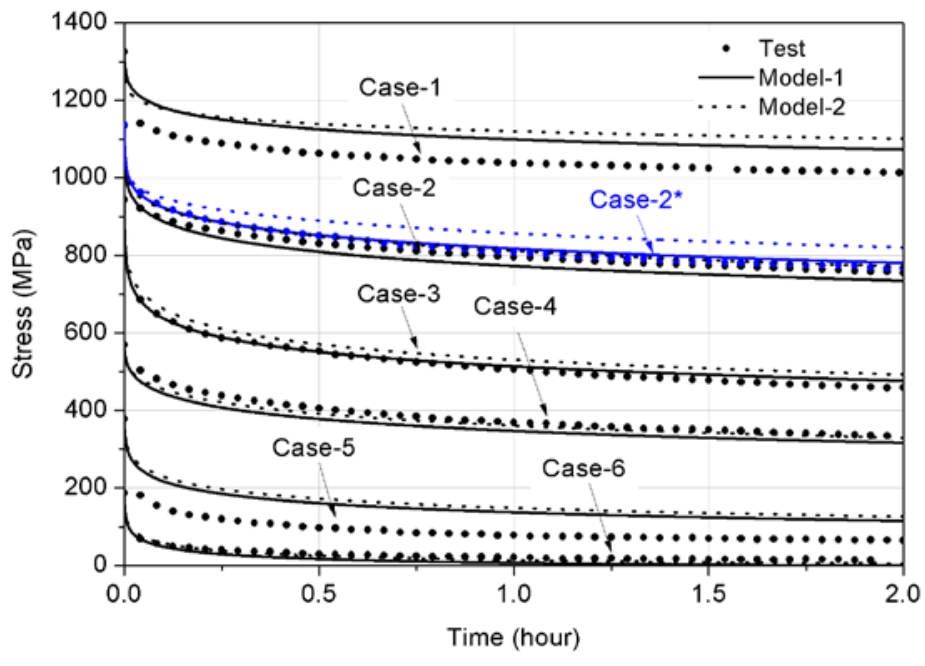

(a) Prestressing steel to GB/T 5224 (Grade 1860) 


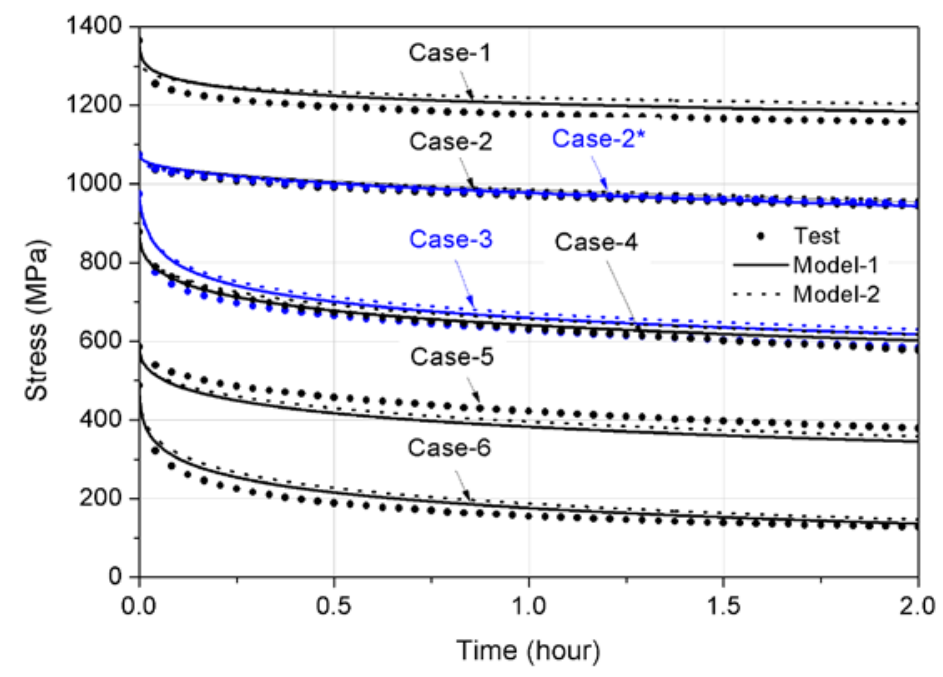

(b) Prestressing steel to BS 5896 (Grade 1860)

Fig. 9. Thermal stress relaxation under various initial stresses and constant temperatures

Results shown in Fig. 9(a) are mostly satisfactory except that the residual stresses for Case-1 and Case-5 predicted numerically are slightly higher than the test results. Results of the repeated tests agree very well with each other as demonstrated by the final residual stresses of $755 \mathrm{MPa}$ for Case- 2 and $767 \mathrm{MPa}$ for Case-2*. Besides, predictions from Model-1 are always slightly lower than those from Model-2, because the thermal creep predicted by Model-2 is slightly larger than that predicted by Model-1 during primary creep.

Similarly in Fig. 9(b), results of the repeated tests agree very well with each other as demonstrated by the final residual stresses of $944 \mathrm{MPa}$ for Case-2 and 951MPa for Case-2*. Interestingly, Case-3 and Case-4 have nearly the same temperature, i.e. $394^{\circ} \mathrm{C}$ and $396.2^{\circ} \mathrm{C}$ respectively, while their residual stresses are quite close to each other after a period of time, even though the former has a higher initial stress. This phenomenon indicates that thermal creep occurs mainly in a short time after the beginning of relaxation at a constant elevated temperature, and then thermal creep becomes smaller and smaller due to the gradual decrease of stress. The predictions from Model-1 are still slightly lower than those from Model-2 for the same reason. 


\section{Discussions}

The test and numerical results shown in Figs. 7 to 8 confirm that the thermal creep parameters obtained are relatively accurate to predict the thermal creep. Besides, the thermal relaxation predicted by the numerical models agree well with the thermal relaxation test results, which further confirms that the thermal creep models and determined parameters can accurately predict the thermal relaxation with different boundary conditions as well. Table 7 gives a summary of thermal creep parameters of prestressing steel available in the literature [12,14], which are based on the same value of thermal creep activation energy $Q_{c}$. However, this may be unreasonable and it may result in inaccurate temperature-compensated creep rate $Z$. Besides, the applicable stress ranges are 690-1000MPa for prestressing steel to ASTM A416 (Grade 1860) and 690-1200MPa for that to BS 5896 (Grade 1860). Extrapolation outside these stress ranges may yield further errors.

The thermal creep parameters obtained in this study and those as shown in Table 5 were used to predict the transient thermal relaxation based on the tests conducted by MacLean [3]. Prestressing steel to ASTM A416 (Grade 1860) was used in the transient thermal relaxation test with the initial stress of 1008MPa. A heating rate of $10^{\circ} \mathrm{C} / \mathrm{min}$ was applied on the heated region until the target temperature of $400^{\circ} \mathrm{C}$ was reached. The temperature was then kept constant for a period of $90 \mathrm{~min}$, and it was finally cooled down. Under the heating-soaking-cooling regime, the variations of stress were recorded. The thermal creep parameters obtained in this study and those from previous work as shown in Table 7 were used to predict the residual stress based on thermal creep Model-1. The predicted and test results are shown in Fig. 10, which shows that BS 5896 (Grade 1860) [14] has the highest predicted residual stress and ASTM A421 (Grade 1725) [12] has the lowest predicted residual stress. The predictions for ASTM A416 (Grade 1860) [14] are quite close to those for BS 5896 (Grade 1860) in this study, and both are the closest to but slightly above the test 
results. The predictions for GB/T 5224 (Grade 1860) are relatively close to but slightly below the test results. Results show that BS 5896 (Grade 1860) [14] and ASTM A421 (Grade 1725) [12] have the highest and lowest thermal creep resistance, respectively. ASTM A416 (Grade 1860) [14] and BS 5896 (Grade 1860) of this study have similar thermal creep resistance, which is above that of GB/T 5224 (Grade 1860) of this study.

Table 7. Thermal creep parameters of prestressing steel in literature

Prestressing steel Thermal creep parameters

ASTM A421

$$
\mathrm{Z}=195.27 \times 10^{6} \sigma^{3}
$$

for $\sigma \leq 172 \mathrm{MPa}$

(Grade 1725) [12]

$$
\mathrm{Z}=8.21 \times 10^{13} e^{0.0145 \sigma}
$$

for $172<\sigma \leq 690 \mathrm{MPa}$

$$
\begin{aligned}
& \varepsilon_{c r, 0}=9.262 \times 10^{-5} \sigma^{0.67} \\
& Q_{c} / R=30556
\end{aligned}
$$$$
\text { for } \sigma \leq 690 \mathrm{MPa}
$$

ASTM A416

$$
\mathrm{Z}=2.7 \times 10^{13} e^{0.012 \sigma}
$$

for $690<\sigma<1000 \mathrm{MPa}$

(Grade 1860) [14]

$$
\begin{aligned}
& \varepsilon_{c r, 0}=1.13 \times 10^{-7} \sigma^{1.63} \quad \text { for } 690<\sigma<1000 \mathrm{MPa} \\
& Q_{c} / R=30556
\end{aligned}
$$

BS 5896

$$
\mathrm{Z}=1.60 \times 10^{12} e^{0.013 \sigma} \quad \text { for } \quad 690<\sigma<1000 \mathrm{MPa}
$$

(Grade 1860) [14]

$$
\begin{array}{ll}
\mathrm{Z}=3.42 \times 10^{4} e^{0.30 \sigma} & \text { for } 1000<\sigma<1200 \mathrm{MPa} \\
\varepsilon_{c r, 0}=1.51 \times 10^{-14} \sigma^{3.90} & \text { for } 690<\sigma<1200 \mathrm{MPa} \\
Q_{c} / R=30556 &
\end{array}
$$




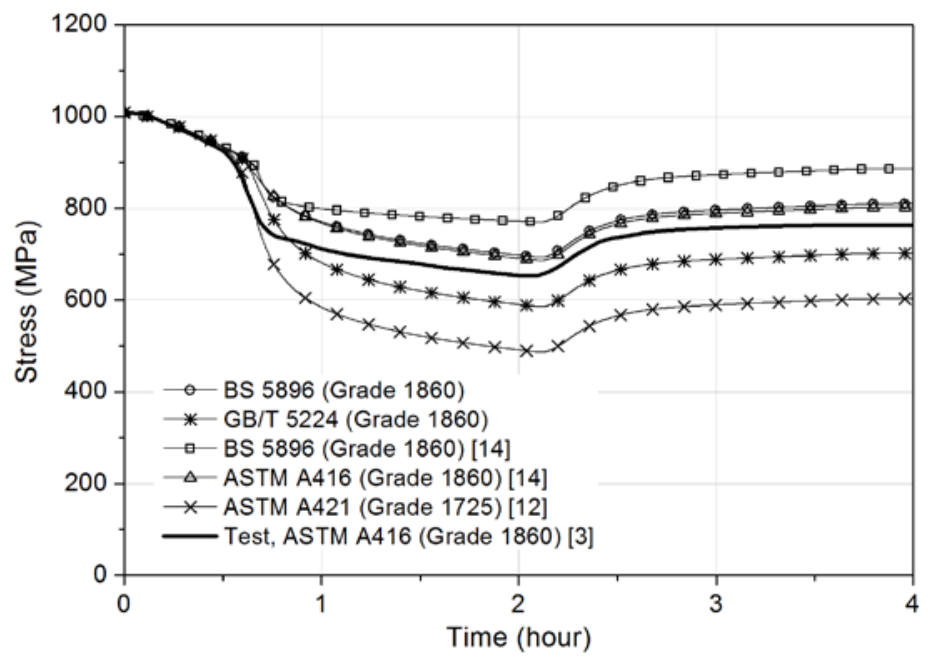

Fig. 10. Transient thermal relaxation based on tests by MacLean [3]

\section{Conclusions}

Thermal creep tests of prestressing steel of Grade 1860 to GB/T5224 and BS 5896 were conducted under constant stresses of 57-1330 MPa and 195-1367 MPa respectively in accordance with ASTM E139-11 over wide stress ranges. A test was stopped when the tendon ruptured or after a period of 2 hours since load application, whichever came first. The parameters of Harmathy's creep model were identified and calibrated based on the test results with a view to extending the recent work of Gales et al. Moreover, tertiary creep was explicitly taken into account adopting the method proposed by Maljaars et al. [21] for aluminium alloys, and the lower limit of tertiary creep was roughly estimated.

Numerical studies were carried out based on the thermal creep parameters obtained and the enhanced thermal creep model taking into account tertiary creep. The model predictions agree well with the creep test results including tertiary creep, which verifies the validity of the enhanced thermal creep model for the thermal creep behaviour of prestressing steel at elevated temperatures. Moreover, thermal relaxation tests of prestressing steel of Grade 1860 to GB/T 5224 and BS 5896 were conducted. Again, the model predictions agree well with the thermal relaxation test results, which verifies the applicability of enhanced thermal creep model to the prediction of thermal relaxation. 
Parametric studies were carried out adopting different sets of thermal creep parameters for Harmathy's creep model including those obtained in this study and others available in the literature, based on the thermal relaxation tests conducted by MacLean [3]. Therefore based on the available data, one may rank the thermal creep resistance in descending order roughly as BS 5896 (Grade 1860), ASTM A416 (Grade 1860), GB/T 5224 (Grade 1860) and ASTM A421 (Grade 1725).

\section{Acknowledgements}

The work described here has been supported by the Research Grants Council (RGC) of Hong Kong Special Administrative Region, China (RGC Project No.: HKU 710012E) and the State Key Laboratory of Subtropical Building Science of South China University of Technology, China (Project No.: 2011KA02).

\section{References}

[1] Abrams M, Cruz C. The behaviour at high temperatures of steel strand for prestressed concrete. PCA Res Development Bulletin, 1961; 134 (3): 8-19.

[2] Holmes M, Anchor R, Cook G, Crook R.. The Effects of Elevated Temperatures on the Strength Properties of Reinforcing and Prestressing Steels. The Struct Eng, 1982; 60(13): 7-13.

[3] MacLean K. Post-fire Assessment of Unbonded Post-Tensioned Concrete Slabs: Strand Deterioration and Prestress Loss. M.Sc. Thesis, Department of Civil Engineering, Queen's University, Kingston, ON, Canada, 2007.

[4] Atienza J, Elices M. Behavior of prestressing steels after a simulated fire: Fire-induced damages. Constr Build Mater, 2009; 23(8): 2932-2940. 
[5] Wang Y, Shen Z, Li Y. Experimental study of the mechanical properties of prestressed steel wire at elevated temperatures. 6th International Conference on Structures in Fire, SiF'10, June 2 - June 4 (2010), East Lansing, MI, United States, DEStech Publications Inc.

[6] Hou X, Zheng W, Kodur V, Sun H. Effect of temperature on mechanical properties of prestressing bars. Constr Build Mater, 2014; 61: 24-32.

[7] Gales J. Transient high-temperature prestress relaxation of unbounded Prestressing tendons for use in concrete slabs. M.Sc. Thesis, Department of Civil Engineering, Queen’s University, Kingston, ON, Canada, 2009.

[8] Gales J, Bisby L, MacDougall C, MacLean K. Transient high-temperature stress relaxation of prestressing tendons in unbonded construction. Fire Saf J, 2009; 44(4): 570-579.

[9] Gales J, Bisby L, Gillie M. Unbonded Post Tensioned Concrete Slabs in Fire- Part I Experimental Response of Unbonded Tendons under Transient Localized Heating. J Struct Fire Eng, 2011;2(3): 139-153.

[10] Gales J, Bisby L, Gillie M. Unbonded Post Tensioned Concrete Slabs in Fire - Part II -Modelling Tendon Response and the Consequences of Localized Heating. J Struct Fire Eng, 2011;2(3):155-171.

[11] Harmathy T. A comprehensive creep model. National Research Council of Canada, Division of Building Research, Ottawa, July 1967.

[12] Harmathy T, Stanzak W. Elevated-Temperature Tensile and Creep Properties of Some Structural and Prestressing Steels. National Research Council of Canada, Division of Building Research, Ottawa, January 1970.

[13] Gales J, Bisby L, Stratford T. New Parameters to Describe High Temperature Deformation of Prestressing Steel Determined Using Digital Image Correction. SEI, 2012;22(4): 476-486. 
[14] Gales J, Bisby L, Stratford T. High Temperature Creep Deformation and Failure Behaviour of Prestressing Steel. 7th International Conference on Structures in Fire, SiF'12, June 6- June 8 (2012), Zurich, Switzerland.

[15] Zhang H, Zheng W. An experimental study on the creep and stress relaxation properties of 1770-९ P5 prestressing steel wires at high temperatures. China Civil Eng J, 2006; 39(8): 7-13. (In Chinese)

[16] GB/T 5224. Steel strand for prestressed concrete. Ministry of Construction of the People's Republic of China, 2003. (In Chinese)

[17] BS 5896. Specification for high tensile steel wire and strand for the prestressing of concrete. British Standards Institution, London, UK, 2012.

[18] Poirier J. Creep of crystals: High-temperature deformation processes in metals, ceramics and minerals. New York: Cambridge University Press; 1985.

[19] Kodur V, Dwaikat M. Effect of high temperature creep on the fire response of restrained steel beams. Mater Struct, 2010;43(10) 1327-1341.

[20] Zener C, Hollolnon J. Effect of Strain Rate on the Plastic Flow of Steel. J Appl Phys, 1944;15: 22.

[21] Maljaars J, Soetens F, Katgerman L. Constitutive model for aluminum alloys exposed to fire conditions. Metall Mater Trans A: Physical Metallurgy and Mater Sci, 2008;39A (4): 778-789.

[22] Zhang L, Wei Y, Au F T K, Li J. Mechanical properties of prestressing steel in and after fire. Magazine of Concrete Research, DOI: 10.1680/jmacr.15.00267.

[23] ASTM E139-11. Standard Test Methods for Conducting Creep, Creep-Rupture, and Stress-Rupture Tests of Metallic Materials. West Conshohocken (PA): American Society for Testing and Materials, 2011. 
[24] ASTM E328-02. Standard Test Methods for Stress Relaxation for Materials and Structures West Conshohocken (PA): American Society for Testing and Materials, 2008.

[25] Wei Y, Au F T K. Numerical modelling of prestressing steel tendons under fire and post-fire conditions. Advances in Structural Engineering, 2015, 18(10):1703-1722. 